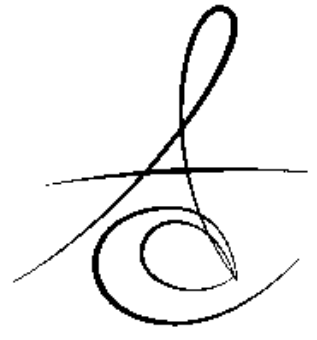

Makale Kodu/Article code: 2545

Makale Gönderilme tarihi; 12.01 .2016

Kabul Tarihi: 22.03.2016

\title{
SERVİKAL ÇÜRÜKSÜZ LEZYONLARDAKİ CAM İYONOMER RESTORASYONLARIN KLİNİK PERFORMANSININ ÖN DEĞERLENDİRMESİ: 1 YILLIK RANDOMİZE KONTROLLÜ ÇALIŞMA
}

\section{THE PRELIMINARY EVALUATION OF CLINICAL PERFORMANCE OF HIGH VISCOSITY GLASS IONOMER RESTORATIONS IN NON-CARIOUS CERVICAL LESIONS: A 1 YEAR RANDOMISED, CONTROLLED TRIAL}

\author{
Doç. Dr. Esra UZER ÇELİ* Araş. Gör. Fatma YILMAZ*
}

Araş. Gör. Betül AKA*

\section{öz}

Amaç: Bu randomize, kontrollü, tek merkezli, bölünmüş ağız (split-mouth) klinik araştırmanın amacı, yüksek viskoziteli cam iyonomer restorasyonların çürüksüz servikal lezyonlardaki 1 yıllık klinik performansını üç aşamalı asitle ve yıka adezivle uygulanan nanohibrit kompozit restorasyonlarla karşılaştırmaktır.

Gereç ve Yöntem: Bu çalışmada 134 tane çürüksüz servikal lezyon, bölünmüş ağız çalışma tasarımına uygun olarak iki gruba ayrıldı. Çalışmada deney grubu olarak yüksek viskoziteli bir cam iyonomer (Equia, GC, Alsip, Illinois, ABD); kontrol grubu olarak üç aşamalı asitle ve yıka adeziv sistemle (Optibond FL, Kerr, Orange, $C A, A B D$ ) uygulanan nanohibrit bir kompozit (G-aenial, GC, Tokyo, Japonya) kullanıldı. Restoratif materyaller üretici firmaların önerileri doğrultusunda uygulandı. Klinik değerlendirme, 1 hafta, 6 ay ve 1 yıl sonra FDI kriterleri kullanılarak yapıldı. Veriler, Friedman 1-way ve Mann-Whitney $U$ testleri kullanılarak analiz edildi $(\alpha=0,05)$.

Bulgular: Bir yıl sonunda, tüm değerlendirme kriterleri açısından iki restoratif materyal arasında istatistiksel olarak anlamlı fark gözlenmezken, yüksek viskoziteli cam iyonomer simanların retansiyonu \%96, nanohibrit kompozitin retansiyonu $\% 100$ bulundu.

Sonuç: Bir yıllık değerlendirme sonrası yüksek viskoziteli cam iyonomer restorasyonların klinik performansı, çürüksüz servikal lezyonlarda nanohibrit kompozitlerle benzer bulundu.

Anahtar kelimeler: Yüksek viskoziteli cam iyonomer, çürüksüz servikal lezyon, nanohibrit kompozit

\section{ABSTRACT}

Aim: The aim of this randomised, controlled, singlecentre, split-mouth clinical trial was to compare the clinical performance of high viscosity glass ionomer restorations in non-carious cervical lesions in comparison to nanohybrid composite restorations applied with a three-step etch \& rinse adhesive system.

Material and Methods: A hundred and thirty four non-carious cervical lesions were included and assignned into two groups, according to split-mouth design. The cervical lesions of the experimental group were restored with a high viscosity glass ionomer (Equia, GC, Alsip, Illinois, USA); while a nanohybrid composite (G-aenial, GC, Tokyo, Japonya) with a three-step etch $\&$ rinse adhesive system (Optibond $\mathrm{FL}$, Kerr, Orange, CA, USA) was used for the control group. All tested restorative materials were used according to the manufacturers' instructions. Clinical evaluation was performed after 1 week, 6 months and 1 year using FDI criteria. Data were analysed using Friedman 1way and Mann-Whitney U tests ( $\alpha=0.05)$.

Results: After 1 year, considering all criteria, there were no significant differences between the two restorative materials. However, high viscosity glass ionomer restorations revealed a retention rate of $96 \%$ in comparison to $100 \%$ of nanohybrid composite restorations.

Conclusions: The clinical performance of high viscosity glass ionomer restorations in non-carious cervical lesions was found similar to the nanohybrid composites after 1 year of clinical service.

Key words: High viscosity glass ionomer, non-carious cervical lesions, nanohybrid composite

${ }^{1}$ İzmir Katip Çelebi Üniversitesi Diş Hekimliği Fakültesi Restoratif Diş Tedavisi A.D 


\section{GİRIŞ}

Çürüksüz servikal lezyonlar fizyolojik ya da patolojik etkenlere bağlı olarak meydana gelen aşınma nedeniyle oluşur. Genel olarak dişin servikal bölgesindeki diş aşınmaları etiyolojik etkenlerine göre abrazyon, erozyon ve abfraksiyon şeklinde sınıflandırılır. ${ }^{1}$ Abrazyon sert yiyecekler, uygun olmayan diş fırçalama, yanlış diş ipi veya kürdan kullanımı, sert cisimlerin dişlerle uzun süre teması, tütün çiğneme ya da kısmi protezlerin kroşeleri gibi fiziksel etkenlere bağlı olarak meydana gelir. Erozyon diş sert dokularının asidik yiyecek içecek tüketimi sebebiyle bakteri olmaksızın kimyasal bir sürece bağlı olarak geri dönüşümsüz bir yıkımını ifade eder. Abfraksiyon ise tekrarlayıcı ve statik oklüzal yüklerin etkisiyle stres altındaki servikal bölgelerde mine kristallerinin yıkımı sonucu gözlenen diş sert doku kayıplarıdır. Klinik ve deneysel çalışmalar kişilerdeki aşınma mekanizmasının nadiren tek başına ilerlediğini, genellikle birbiriyle etkileşim içinde olduğunu göstermiştir. ${ }^{2,3}$ Klinikte, keskin, belirgin kenarları, sert ve pürüzsüz yüzeyleri bulanan abrazyon lezyonlarına erozyon da eşlik ederse daha yuvarlak, geniş ve sığ bir şekilde izlenir. Abfraksiyon lezyonları ise keskin çizgi açıları bulunan kama şeklindeki lezyonlar olarak karşımıza çıkar.

Servikal lezyonların tedavisinde ilk olarak koruyucu önlemler uygulanmalıdır. Ancak plak birikimine neden olan madde kaybı, dentin hassasiyeti, kötü estetik görünüm, gıda sıkışması ve pulpanın açığa çıkma olasılığı gibi durumlar varsa restoratif tedavi seçenekleri uygulanır. ${ }^{1}$ Restoratif tedavide klinik başarı lezyonların yoğun stres altında olması, sklerotik yapısı ve bu bölgede retantif alanların azlığı nedeniyle zordur. Özellikle oklüzal kuvvetlerden kaynaklanan servikal bölgedeki yoğun stres alanları hem lezyonun ilerlemesine sebep olur, hem de restorasyonun bağlantısını başarısızlığa uğratır., ${ }^{4,5}$ Çürüksüz servikal lezyonların restore edilmesi için çoğunlukla kompozit rezinler, kompomerler ve cam iyonomer simanlar kullanılır. Günümüzde estetik özellikleri, geniş renk seçenekleri ve aşınmaya karşı olan dirençleri nedeniyle kompozit rezinler daha çok tercih edilmektedir. Ancak yeni geliştirilen restoratif cam iyonomerlerin de bu amaçla kullanımları giderek artmaktadır. ${ }^{6}$ Geleneksel cam iyonomerlerin partikül büyüklükleri azaltılıp dağıım oranları değiştirilerek geliştirilen bu materyalin geleneksel tipteki cam iyonomerlere göre fiziksel, mekanik ve estetik özellikleri ve neme karşı hassasiyetleri iyileştirilmiştir. ${ }^{7-11}$ Geleneksel cam iyonomerlere göre daha translusent olup renk seçenekleri daha fazladır. Literatürde, yüksek viskoziteli cam iyonomerlerin Sınıf 1 ve Sınıf 2 restorasyonlardaki klinik performansı başarılı bulunmuştur. ${ }^{8,12}$ Ancak bu materyallerin çürüksüz servikal lezyonlardaki klinik performanslarıyla ilgili yeterli sayıda çalışma bulunmamaktadır. Bu çalışmanın amacı, çürüksüz servikal lezyonlarda yüksek viskoziteli cam iyonomer restorasyonların 1 yıllık klinik performansını üç aşamalı asitle ve yıka adezivle uygulanan nanohibrit kompozit restorasyonlarla karşılaştırmaktır. Çalışmamızda, "yüksek viskoziteli cam iyonomer restorasyonlar ile üç aşamalı asitle ve yıka adeziv sistemle birlikte uygulanan nanohibrit kompozit rezin restorasyonların 1 yıllık klinik performansları arasında fark yoktur" sıfır hipotezi test edilmiştir.

\section{GEREÇ VE YÖNTEM}

\section{Araştırmanın Niteliği ve Örneklem Büyüklügü}

Çalışmada kullanılacak denek sayılarını belirleyebilmek amacı ile G*Power (G*Power Ver. 3.0.10, Franz Faul, Üniversität Kiel, Almanya, http:// www.psycho.uni-duesseldorf.de/aap/projects/gpower) paket programı kullanıldı. Çalışmada yüksek viskoziteli cam iyonomer ve nanohibrit kompozit rezin arasındaki $\mathrm{f}=0.25^{\prime}$ lik (orta) etki farkını en az $\% 80$ güç ile belirleyebilmek için $\alpha=0.05$ tip I hata için her bir grupta en az 65 restorasyona ihtiyaç olduğu belirlendi.

İzmir Katip Çelebi Üniversitesi Restoratif Diş Tedavisi kliniğine başvuran 27 hasta bu randomize, kontrollü, tek merkezli, bölünmüş ağız (split-mouth) klinik çalışmaya dahil edilmek üzere muayene edildi. Çalışma kriterlerine uygun olmadığı için 5 hasta çalışmaya dahil edilmedi ve ortalama yaşları 47,8 (yaş aralığı 34 - 63) olan toplam 22 hasta (11 bayan, 11 erkek) çalışmaya dahil edildi. Araştırma protokolü İzmir Katip Çelebi Üniversitesi Tıp Fakültesi Etik Kurulu'nda onaylandı (2013/67). Tedavi işlemleri ve olası riskler anlatıldıktan sonra hastalardan bilgilendirilmiş gönüllü onam formu yazılı ve imzalı bir şekilde çalışmanın başında alındı.

\section{Hasta seçimi}

Çalışmaya dahil edilme kriterleri; (1) en az iki çürüksüz, simetrik servikal lezyon varlığı, (2) 18 yaş üstü hastalar ve daimi dişler, (3) servikal kenarın 
dentinde sonlanması, (4) karşıt ve komşu dişlerin olması, (5) canlı dişler ve basınca duyarlıık, spontan ağrı gibi pulpitis semptomlarının olmaması, (6) periyodik kontrollere gelebilme şeklinde belirlendi. Çalışmadan dişlanma kriterleri ise; (1) şiddetli periodontal hastalık, (2) sistemik hastalık varlığı, (3) kullanılacak olan materyallerden herhangi birine karşı alerjik reaksiyon, (4) kötü ağız hijyeni, (5) hamilelik ve emzirme, (6) çapraşıklık dolayısıyla aşırı yüke maruz kalan dişler, (7) çürüklü lezyonlar, (8) bruksizm gibi parafonksiyonel rahatsızlıklar, (9) Kuzey Carolina Üniversitesi'nin sınıflandırmasına göre 4. derecede skleroz varlığı, ${ }^{13}$ (10) devam eden ortodontik tedavi ve (11) flor ya da hassasiyet giderici ajan kullanımı şeklinde belirlendi.

\section{Lezyon seçimi}

Çalışmaya en az iki simetrik dişindeki çürüksüz servikal lezyonun tedavisi için kliniğimize başvuran 22 adet hasta ve toplam 134 adet lezyon dahil edildi. Alt ve üst çenedeki tipik kama ya da fincan tabağı şeklindeki lezyonlar restore edildi. Lezyonlar dişlerin bukkal yüzeylerinde bulunmaktaydı ancak, üç adet lezyon ara yüze ulaşmaktaydı. Lezyonların dişeti kenarı dentinde, insizal/oklüzal kenarı ise minede sonlanmaktaydı.

Çürüksüz servikal lezyonlar lezyon derinliği, skleroz derecesi ve operasyon öncesi hassasiyet varlığı açısından sınıflandırıldı (Tablo 1). En az 2 simetrik lezyonu (bir çift) bulunan hastaların bir tanesinde 2, beş tanesinde 4 , on altı tanesinde 6 ve iki tanesinde 8 simetrik lezyon bulunmaktaydı. Deney grubunda lezyonların \%70'inde skleroz görülmezken, \%20'si hafif sklerotik, \%10'u orta derecede sklerotik idi. Kontrol grubunda ise lezyonların \%61'inde skleroz görülmezken, \%25'i hafif sklerotik, \%14'ü orta derecede sklerotik idi.

Deneklerin gruplara atanması (randomizasyon)

Çalışma randomize deney olduğundan dişlerin gruplara atanması için tam randomizasyon yapıldı. ${ }^{14}$ Excel programı kullanılarak randomizasyon tablosu hazırlandı. ${ }^{15}$ Öncelikle simetrik dişler eşleştirildi. Daha sonra eşleştirilen dişler FDI sistemine göre olan numaraları doğrultusunda randomizasyon tablosunda küçükten büyüğe doğru sıralandı. Restore edilecek dişler randomizasyon tablosuna göre rastgele deney ve kontrol grubuna atandı.

\section{Restoratif işlem/er}

Tüm restoratif işlemler tek bir deneyimli diş hekimi tarafından gerçekleştirildi. Diş hekiminin restoratif işlemler sırasındaki kalibrasyonunu sağlamak
Tablo 1. Değerlendirme Kriterleri ve Lezyon Sayıları

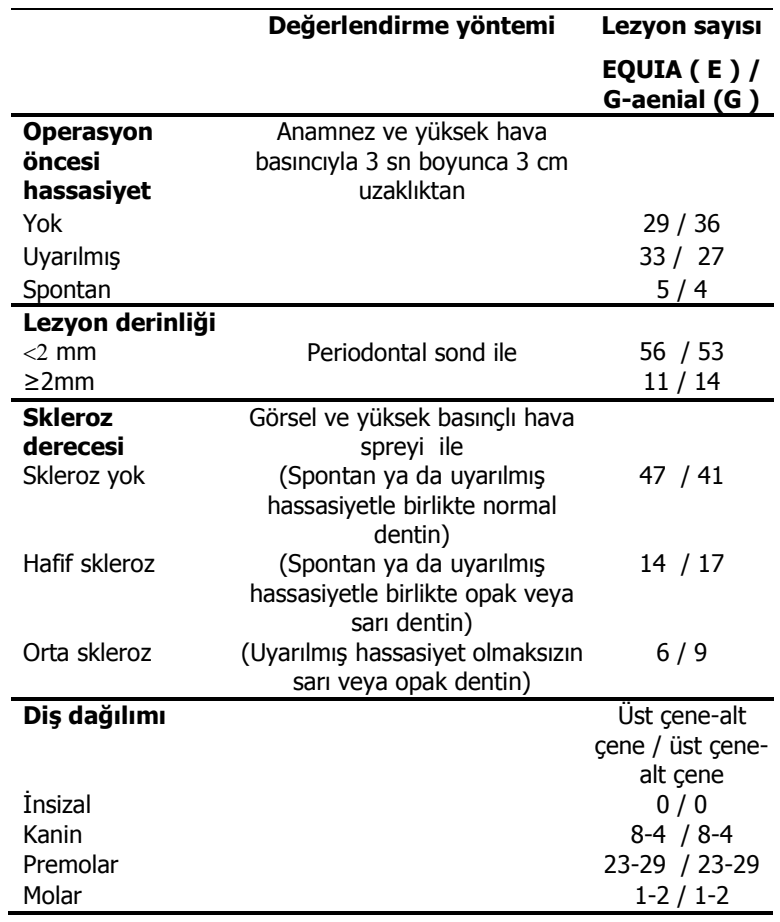

amacıyla öncelikle çekilmiş insan dişlerinde hazırlanan Sınıf 5 kavitelerin test edilecek materyaller ile restorasyonu yapıldı. Daha sonra çalışmaya dahil edilmeyecek hastalarda her bir materyal ile 10 adet restorasyon olacak şekilde bir deneme çalışması yapıldı. Bu çalışmada deney grubu olarak yüksek viskoziteli cam iyonomer restoratif materyel olan Equia (GC, Alsip, Illinois, ABD) (Cis); kontrol grubu olarak nanohibrit kompozit rezin olan G-aenial (GC, Tokyo, Japonya) (Kom) kullanıldı. Çalışmaya dahil edilen simetrik lezyonlardan biri Cis ile, diğeri ise asitle ve yıka tekniğiyle birlikte Kom ile restore edildi. Kullanılan materyaller, içerikleri ve kod numaraları Tablo 2'de verilmiştir.

Restoratif işlemler öncesinde tüm hastalara ağız hijyen eğitimi ve detertraj içeren rutin profesyonel ağız bakımı yapıldı. Dişlerin yüzeyindeki yumuşak doku eklentileri flor içermeyen pomza patı ile temizlendi. Lezyonların başlangıç fotoğrafları ekartör ve ağız aynası yardımı ile D80 DSLR (Nikon Corporation, Tokyo, Japonya) dijital fotoğraf makinası ile alındı. Dişlerin renkleri ağız içi dental spektrofotometre (Spektroshade, MHT Optic Research AG, Niederhasli,

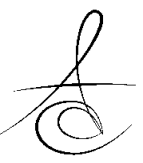


Atatürk Üniv. Diş Hek. Fak. Derg.

UZER ÇELİK, YILMAZ,

J Dent Fac Atatürk Uni

Cilt:26, Sayı:2, Yıl: 2016, Sayfa: 231-238

Tablo 2. Çalışmada Kullanılan Materyaller ve İçerikleri

\begin{tabular}{|c|c|c|c|}
\hline Materyal & Üretici firma & İçeriği & $\begin{array}{l}\text { Kod } \\
\text { numaraları }\end{array}$ \\
\hline Cavity conditioner & GC, Alsip, Illinois, ABD & $\% 20$ 'lik poliakrilik asit & 1310241 \\
\hline EQUIA & GC, Alsip, Illinois, ABD & Poliakrilik asit, alümina-silikat cam, distile su & $\begin{array}{l}\text { A2: } 1301251 \\
A 3: 1208091\end{array}$ \\
\hline EQUIA Coat & GC, Alsip, Illinois, ABD & Metilmetakrilat, kolloidal silika, kamforokinon & 1112121 \\
\hline G-aenial & GC, Tokyo, Japonya & $\begin{array}{l}\text { Metakrilat monomerler, silika, stronsiyum lantanid } \\
\text { florür, fumed silika, pigmentler, katalizörler }\end{array}$ & $\begin{array}{l}\text { B1: } 1110282 \\
\text { A1: } 1202081 \\
\text { A2: } 1202112 \\
\text { A3: } 1202072\end{array}$ \\
\hline \multirow[t]{3}{*}{ Optibond FL } & Kerr, Orange, CA, ABD & Jel asit: $\% 37,5$ fosforik asit, silika, kalınlaştırıcı & 4853883 \\
\hline & & $\begin{array}{l}\text { Primer: HEMA, GPDM, PAMM, etanol, su, foto- } \\
\text { insiyatör }\end{array}$ & 4848017 \\
\hline & & $\begin{array}{l}\text { Adeziv: TEGDMA, UDMA, GPDM, HEMA, Bis-GMA, } \\
\text { doldurucu, foto-insiyatör }\end{array}$ & 4851976 \\
\hline
\end{tabular}

HEMA, hidroksietil metakrilat; UDMA, üretan dimetakrilat; TEGDMA, trietilenglikol-dimetakrilat; 4-MET, 4-metakriloloksi etil trimellitik asit; GPDM, gliserol fosfat dimetakrilat; PAMM, fitalik asit monoetil metakrilat; Bis-GMA, bisfenol-glisidil metakrilat.

Tablo 3. FDI Kriterlerine Göre Restorasyonların Sınıflandırılması ${ }^{16}$

\begin{tabular}{|c|c|c|c|c|c|c|c|c|c|c|c|}
\hline & & \multicolumn{4}{|c|}{ G-aenial } & \multicolumn{4}{|c|}{ EQUIA } & \multicolumn{2}{|c|}{ p değeri } \\
\hline & & $\begin{array}{c}\text { Başlangıç } \\
\text { skorları }\end{array}$ & $\begin{array}{c}6 \text { ay } \\
\text { sonraki } \\
\text { skorlar } \\
\end{array}$ & $\begin{array}{c}1 \text { yıl } \\
\text { sonraki } \\
\text { skorlar } \\
\end{array}$ & $\begin{array}{c}\text { Klinik } \\
\text { olarak } \\
\text { kabul }\end{array}$ & $\begin{array}{c}\text { Başlangıç } \\
\text { skorları }\end{array}$ & $\begin{array}{c}6 \text { ay } \\
\text { sonraki } \\
\text { skorlar } \\
\end{array}$ & $\begin{array}{c}1 \text { yıl } \\
\text { sonraki } \\
\text { skorlar } \\
\end{array}$ & $\begin{array}{c}\text { Klinik } \\
\text { olarak } \\
\text { kabul }\end{array}$ & $\begin{array}{l}\text { E / G } \\
6 . \text { ay } \\
\end{array}$ & $\begin{array}{l}\text { E /G } \\
\text { 1. yil }\end{array}$ \\
\hline & & $(1 / 2 / 3 / 4 / 5)$ & $(1 / 2 / 3 / 4 / 5)$ & $(1 / 2 / 3 / 4 / 5)$ & $\begin{array}{l}\text { edilen } \\
\text { restoras } \\
\text {-yonlar }\end{array}$ & $(1 / 2 / 3 / 4 / 5)$ & $(1 / 2 / 3 / 4 / 5)$ & $(1 / 2 / 3 / 4 / 5)$ & $\begin{array}{c}\text { edilen } \\
\text { restoras- } \\
\text { yonlar }\end{array}$ & & \\
\hline \multirow[t]{5}{*}{$\begin{array}{c}\text { Estetik } \\
\text { özellikler }\end{array}$} & Yüzey parlaklığı & $67 / 0 / 0 / 0 / 0$ & $67 / 0 / 0 / 0 / 0$ & $67 / 0 / 0 / 0 / 0$ & $\% 100$ & $67 / 0 / 0 / 0 / 0$ & $65 / 1 / 0 / 0 / 0$ & $62 / 2 / 0 / 0 / 0$ & $\% 100$ & 0,232 & 0,135 \\
\hline & Yüzey renklenmesi & $67 / 0 / 0 / 0 / 0$ & $67 / 0 / 0 / 0 / 0$ & $67 / 0 / 0 / 0 / 0$ & $\% 100$ & $67 / 0 / 0 / 0 / 0$ & $66 / 0 / 0 / 0 / 0$ & $64 / 0 / 0 / 0 / 0$ & $\% 100$ & 0,368 & 0,218 \\
\hline & Kenar renklenmesi & $67 / 0 / 0 / 0 / 0$ & $67 / 0 / 0 / 0 / 0$ & $67 / 0 / 0 / 0 / 0$ & $\% 100$ & $67 / 0 / 0 / 0 / 0$ & $66 / 0 / 0 / 0 / 0$ & $64 / 0 / 0 / 0 / 0$ & $\% 100$ & 0,368 & 0,218 \\
\hline & Renk uyumu ve Trans. & $65 / 2 / 0 / 0 / 0$ & $65 / 2 / 0 / 0 / 0$ & $65 / 2 / 0 / 0 / 0$ & $\% 100$ & $63 / 2 / 2 / 0 / 0$ & $62 / 2 / 2 / 0 / 0$ & $60 / 2 / 2 / 0 / 0$ & $\% 100$ & 0,172 & 0,097 \\
\hline & Estetik anotomik form & $67 / 0 / 0 / 0 / 0$ & $67 / 0 / 0 / 0 / 0$ & $67 / 0 / 0 / 0 / 0$ & $\% 100$ & $67 / 0 / 0 / 0 / 0$ & $66 / 0 / 0 / 0 / 0$ & $64 / 0 / 0 / 0 / 0$ & $\% 100$ & 0,368 & 0,218 \\
\hline \multirow{4}{*}{$\begin{array}{c}\begin{array}{c}\text { Fonksiyo- } \\
\text { nel }\end{array} \\
\text { özellikler }\end{array}$} & Mat. kırık ve Ret. prob. & $67 / 0 / 0 / 0 / 0$ & $67 / 0 / 0 / 0 / 0$ & $67 / 0 / 0 / 0 / 0$ & $\% 100$ & $67 / 0 / 0 / 0 / 0$ & $66 / 0 / 0 / 0 / 1$ & $64 / 0 / 0 / 0 / 3$ & $\% 96$ & 0,110 & 0,086 \\
\hline & Kenar uyumu & $67 / 0 / 0 / 0 / 0$ & $67 / 0 / 0 / 0 / 0$ & $67 / 0 / 0 / 0 / 0$ & $\% 100$ & $67 / 0 / 0 / 0 / 0$ & $66 / 0 / 0 / 0 / 0$ & $64 / 0 / 0 / 0 / 0$ & $\% 100$ & 0,368 & 0,218 \\
\hline & Aşınma & $67 / 0 / 0 / 0 / 0$ & $67 / 0 / 0 / 0 / 0$ & $67 / 0 / 0 / 0 / 0$ & $\% 100$ & $67 / 0 / 0 / 0 / 0$ & $66 / 0 / 0 / 0 / 0$ & $64 / 0 / 0 / 0 / 0$ & $\% 100$ & 0,368 & 0,218 \\
\hline & Hasta görüşü & $67 / 0 / 0 / 0 / 0$ & $67 / 0 / 0 / 0 / 0$ & $67 / 0 / 0 / 0 / 0$ & $\% 100$ & $67 / 0 / 0 / 0 / 0$ & $66 / 0 / 0 / 0 / 0$ & $64 / 0 / 0 / 0 / 0$ & $\% 100$ & 0,368 & 0,218 \\
\hline \multirow[t]{6}{*}{$\begin{array}{l}\text { Biyolojik } \\
\text { özellikler }\end{array}$} & Postop. hass. ve Vit. & $67 / 0 / 0 / 0 / 0$ & $67 / 0 / 0 / 0 / 0$ & $67 / 0 / 0 / 0 / 0$ & $\% 100$ & $67 / 0 / 0 / 0 / 0$ & $66 / 0 / 0 / 0 / 0$ & $64 / 0 / 0 / 0 / 0$ & $\% 100$ & 0,368 & 0,218 \\
\hline & $\begin{array}{c}\text { Çürük, Eroz. ve } \\
\text { Abraz. }\end{array}$ & $67 / 0 / 0 / 0 / 0$ & $67 / 0 / 0 / 0 / 0$ & $67 / 0 / 0 / 0 / 0$ & $\% 100$ & $67 / 0 / 0 / 0 / 0$ & $66 / 0 / 0 / 0 / 0$ & $64 / 0 / 0 / 0 / 0$ & $\% 100$ & 0,368 & 0,218 \\
\hline & Diş bütünlüğü & $67 / 0 / 0 / 0 / 0$ & $67 / 0 / 0 / 0 / 0$ & $67 / 0 / 0 / 0 / 0$ & $\% 100$ & $67 / 0 / 0 / 0 / 0$ & $66 / 0 / 0 / 0 / 0$ & $64 / 0 / 0 / 0 / 0$ & $\% 100$ & 0,368 & 0,218 \\
\hline & Periyodontal cevap & $67 / 0 / 0 / 0 / 0$ & $67 / 0 / 0 / 0 / 0$ & $67 / 0 / 0 / 0 / 0$ & $\% 100$ & $67 / 0 / 0 / 0 / 0$ & $66 / 0 / 0 / 0 / 0$ & $64 / 0 / 0 / 0 / 0$ & $\% 100$ & 0,368 & 0,218 \\
\hline & Komşu mukoza & $67 / 0 / 0 / 0 / 0$ & $67 / 0 / 0 / 0 / 0$ & $67 / 0 / 0 / 0 / 0$ & $\% 100$ & $67 / 0 / 0 / 0 / 0$ & $66 / 0 / 0 / 0 / 0$ & $64 / 0 / 0 / 0 / 0$ & $\% 100$ & 0,368 & 0,218 \\
\hline & Ağız ve genel sağlık & $67 / 0 / 0 / 0 / 0$ & $67 / 0 / 0 / 0 / 0$ & $67 / 0 / 0 / 0 / 0$ & $\% 100$ & $67 / 0 / 0 / 0 / 0$ & $66 / 0 / 0 / 0 / 0$ & $64 / 0 / 0 / 0 / 0$ & $\% 100$ & 0,368 & 0,218 \\
\hline $\begin{array}{r}\text { Toplam b } \\
\text { oran }\end{array}$ & aşarı & & $\% 100$ & & $\% 100$ & & $\% 98,5$ & & $\% 96$ & & \\
\hline
\end{tabular}


İsviçre) yardımıyla belirlendi. Lezyonların derinlikleri WHO sondu kullanılarak Tablo 1'deki çizelgeye göre skorlandı. Hastalara ait kişisel bilgiler ve hastaların ağız hijyeni, sigara kullanma alışkanlığı, renklendirici ajan kullanma sıklığı, dişlerin vitalitesi, skleroz derecesi ve operasyon öncesi hassasiyet varlığı gibi dişe ait bilgiler hasta formlarına kaydedildi.

Restoratif işlemler sırasında çalışma alanının izolasyonu pamuk pelet, retraksiyon ipi ve tükürük emici ile sağlandı. Operatif işlemler için lokal anestezi yapılmadı ve lezyonlara bizotaj uygulanmadı.

Test edilecek restoratif materyaller üretici firmaların önerileri doğrultusunda uygulandı. Restorasyonların yapım aşamasında herhangi bir matris sistemi kullanılmadı. Yüksek viskoziteli cam iyonomer kaviteye uygulanmadan önce Cavity Conditioner (GC, Alsip, Illinois, ABD) mine ve dentine 10 sn süreyle uygulandı, hava-su spreyi ile yıkandı ve hafifçe kurutuldu. Kapsül formunda kullanılan yüksek viskositeli cam iyonomer (Equia) 10 sn karıştıııldı ve tek tabaka olarak lezyon yüzeyine uygulandı. Bitirme işleminden sonra cam iyonomer yüzey verniği (Equia Coat, GC, Alsip, Illinois, ABD) uygulandı ve 20 sn LED ışık cihazı (Valo, Ultradent Products Inc., South Jordan, UT, ABD) ile 1000 $\mathrm{mW} / \mathrm{cm}^{2}$ lik standart güçteki ışıkla sertleştirildi.

Kom grubuna dahil edilen lezyonlarda üç aşamalı asitle ve yıka adeziv sistem (Optibond $\mathrm{FL}$, Kerr, Orange, $C A, A B D$ ) kullanıldı. Mine ve dentin yüzeyine ilk olarak \%37, $5^{\prime}$ lik ortofosforik asit (Kerr) 15 sn süreyle uygulandı. Asit yıkanarak uzaklaştıııı ve lezyon yüzeyi 15 sn süreyle hafifçe kurutuldu. Primer mine ve dentin yüzeyine 15 sn süreyle ovalama hareketiyle sürüldü ve 5 sn hafif hava uygulanarak çözücü uzaklaştıııld. Bağlayıcı ajan 15 sn süreyle ovalama hareketiyle lezyon yüzeyine uygulandı. Hafif hava ile inceltildi ve 10 sn süreyle LED ışık cihazı ile $1000 \mathrm{~mW}$ $/ \mathrm{cm}^{2}$ lik standart güçteki ışıkla sertleştirildi. Nanohibrit kompozit (G-aenial) $2 \mathrm{~mm}$ tabakalar halinde uygulandı ve her tabaka 10 sn süreyle LED ışık cihazı ile 1000 $\mathrm{mW} / \mathrm{cm}^{2}$ lik standart güçteki ışıkla sertleştirildi.

Bitirme işlemleri aynı seansta yüksek devirde sarı kuşak elmas bitirme frezi ile su soğutması altında yapıldı. Parlatma işlemi sadece kompozit restorasyonlara uygulandı ve bu işlem için düşük devirde alüminyum oksit içerikli diskler (Sof-Lex, 3M ESPE, St. Paul, $M N, A B D$ ) kullanıldı.

Değerlendirme işlemleri

Hastalar restorasyonlarının klinik performans- larının incelenmesi amacıyla yapım aşamasında yer almayan iki deneyimli gözlemci tarafından 1. haftada, 6. ayda ve 1. yılda FDI kriterlerine göre değerlendirildi. ${ }^{16}$ Gözlemcilerin hangi dişe hangi restorasyon yapıldığı hakkında önceden bilgileri yoktu. Fonksiyonel (materyalde kırık veya retansiyon problemi, kenar uyumu, aşınma, hasta görüşü), estetik (yüzey parlaklığı, yüzey renklenmesi, kenar renklenmesi, renk uyumu, translusentlik, estetik anatomik form) ve biyolojik (postoperatif hassasiyet ve vitalite, çürük oluşumu veya erozyon, abrazyon, diş bütünlüğü, periodontal cevap, komşu mukoza, ağız ve genel sağlı) kriterleri 1 'den 5'e kadar olan skalaya göre skorlandı. Skor 1, 2 ve 3 klinik olarak kabul edilebilirken, skor 4 ve 5 restorasyonlarda başarısızlık olarak kabul edildi. Skorlamalar sırasında gözlemciler arası anlaşmazıı olduğu durumlarda tartışılarak ortak bir karara varıldı. Çalışmadan önce gözlemcilerin kendi içlerindeki ve birbirleriyle olan kalibrasyonunu sağlamak ve güvenilirliklerini test etmek amacıyla çalışmaya dahil edilmeyecek olan 20 Sınıf 5 restorasyon rastgele seçildi ve değerlendirildi. Istatistiksel analiz

İstatistiksel analiz için SPSS programı 20.0 versiyonu (IBM Corporation, New York, ABD) kullanıldı. Veriler, Friedman 1-way ve Mann-Whitney $U$ testleri kullanılarak analiz edildi. Deney grubu ve kontrol grubunun lezyon derinliği, skleroz derecesi ve operasyon öncesi hassasiyet varlığı skorları Mann-Whitney U testi ile karşışşırıldı. Değerlendirme süreleri boyunca (1. hafta, 6 . ay ve 1 . yılda) tüm kriterlerdeki skor farklılıkları Friedman 1-way testi ile analiz edildi. MannWhitney $U$ testi ile her bir kriter için farklı değerlendirme sürelerinde her iki restoratif materyalin skorları karşılaştıııldı. Tüm testlerde $a=0,05$ olarak kabul edildi.

\section{BULGULAR}

Bir yıl sonunda tüm hastalar kontrol edilebildi. Klinik değerlendirme ve istatistiksel analiz sonuçları Tablo 3'de verilmiştir.

Çürüksüz servikal lezyonların başlangıç lezyon derinliği, skleroz derecesi ve operasyon öncesi hassasiyet skorları açısından iki grup arasında istatistiksel olarak anlamlı bir fark bulunmadı. Cis ile Kom gruplarının başlangıç estetik, fonksiyonel ve biyolojik kriterleri arasında da istatistiksel olarak anlamlı fark gözlenmedi. Ara yüze ulaşan lezyonlardan biri Cis,

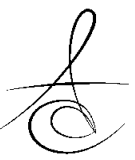


diğer ikisi Kom grubunda yer aldı. Arayüze ulaşan restorasyonlarda 6 . ay ve 1 . yılda başlangıç skorlarına göre değişim gözlenmedi.

Altı ay sonra Cis grubundan 1 restorasyon tamamıyla düştü (\%98,5 retansiyon), Kom grubunda ise retansiyon oranı $\% 100$ idi. Ancak tüm değerlendirme kriterleri açısından her iki grup arasında istatistiksel olarak anlamlı bir fark gözlenmedi.

Bir yıl sonra 3 adet Cis restorasyon tamamıla düştü. Böylece Cis grubunun materyalde kırık ve retansiyon problemi kriteri açısından klinik başarı oranı $\% 96$ 'ya geriledi. Kom grubunda ise retansiyon oranı 1 yıl sonra \%100 idi. Ancak tüm değerlendirme kriterleri açısından her iki grup arasında istatistiksel olarak anlamlı bir fark gözlenmedi.

Kom grubunun tüm değerlendirme kriterleri açısından 6. aydaki ve 1 . yıldaki skorları başlangıç skorlarıyla aynı kaldı. Cis grubunda ise yüzey parlaklığı açısından 1 restorasyona 6 . ayda 2 skoru (iyi) verilirken, 2 restorasyona 1 . yılda 2 skoru (iyi) verildi. Altıncı ayda 1 Cis restorasyon kayıpken, 1 . yılda 2 Cis restorasyon daha düştü. Ancak Cis grubunda da tüm kriterler açısından başlangıç, 6. ay ve 1 . yıl skorları arasında istatistiksel olarak bir fark gözlenmedi.

Düşen Cis restorasyonlar ağızdaki konumu, skleroz derecesi ve derinlik açısından değerlendirildiğinde, 1 tanesi alt çenede, 2 tanesi üst çenede yer almaktaydı. Üçü de hafif sklerotik yapıdaydı. Alt çenedeki lezyonun derinliği $2 \mathrm{~mm}$ 'den az, üst çenedeki lezyonlardan birisinin derinliği 2 mm'den az, diğerinin 2 mm'den fazla idi (Resim 1).

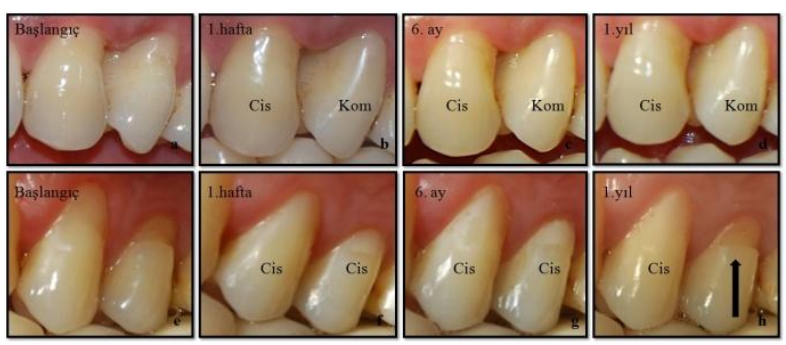

Resim 1a-1d: Retansiyon kaybı gözlenmeyen Kom ve Cis restorasyonlar, 1e-1h: Bir yıl sonra retansiyon kaybı gözlenen Cis restorasyon

\section{TARTIŞMA}

Servikal lezyonların sklerotik yapısı, bu bölgede retantif alanların azlığı, oklüzal kuvvetlerden kaynaklanan yoğun stres alanları nedeniyle restoratif materyallerin Sınıf 5 kavitelere bağlantısı zordur. ${ }^{4,5} \mathrm{Bu}$ nedenle diş hekimliğinde, restoratif materyallerin diş dokularına bağlanma performansını değerlendirmek amacıyla, özellikle servikal lezyonlardaki klinik performansları değerlendirilir. Buna ilaveten, materyallerin klinik başarısı ve fiziksel özelliklerinin doğru değerlendirilebilmesi için in vitro sonuçların, klinik araştırmalarla mutlaka desteklenmesi de gerekmektedir. Çalışmamız, sonuçları etkileyebilecek lezyonların ağızdaki konumuna bağlı değişkenlerden, oklüzyondan ve diş fırçalama alışkanlıklardan kaynaklanan etkileri en aza indirmek için randomize ve bölünmüş ağız klinik araştırma şeklinde tasarlanmıştır.

Çürüksüz servikal lezyonların restorasyonunda çoğunlukla kompozit rezinler, kompomerler ve cam iyonomer simanlar kullanılmaktadır. Nanohibrit kompozit rezinler geliştirilmiş estetik özellikleri, geniş renk seçenekleri ve aşınmaya karşı olan dirençleri nedeniyle anterior ve posterior çürüksüz servikal lezyonlarda başarıyla kullanılmaktadır. ${ }^{17,18}$ Kompozit rezinler estetik avantajları nedeniyle daha sık kullanılmalarına rağmen; kullanım kolaylığı, diş dokularına kimyasal bağlanabilme yetenekleri ve florür salma özellikleri nedeniyle cam iyonomer simanlar da Sınıf 5 lezyonların tedavisinde tercih edilmektedir. Bu çalışmada, yüksek viskoziteli bir cam iyonomer simanın çürüksüz servikal lezyonlardaki 1 yıllık klinik performansı nanohibrit bir kompozit rezinle karşılaştırılmıştır.

Çalışmada test edilen "yüksek viskoziteli cam iyonomer restorasyonlar ile üç aşamalı asitle ve yıka adeziv sistemle birlikte uygulanan nanohibrit kompozit rezin restorasyonların 1 yıllık klinik performansları arasında fark yoktur" sıfır hipotezi kabul edilmiştir. Ancak 1 yıl sonunda 3 adet Cis restorasyonda retansiyon kaybı (\%96 retansiyon) gözlenmiştir. Kom grubunda retansiyon kaybı gözlenmezken, iki grup arasında retansiyon açısından istatistiksel olarak anlamlı fark gözlenmemiştir. Literatürde, Sınıf 5 restorasyonlarda geleneksel cam iyonomer siman kullanımının erken retansiyon kaybı riskini artırdığı bildirilmiştir. ${ }^{19}$ Ayrıca geleneksel cam iyonomerlerle yapılan bu tür restorasyonlarda kompozit rezinlere göre daha fazla kenar uyumu ve aşınma problemleri

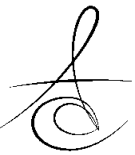


gözlenmiştir. ${ }^{20}$ Yüksek viskositeli cam iyonomerlerin klinik performansını değerlendiren retrospektif bir çalışmada Sınıf 1 ve Sınıf 2 kavitelerde bu materyalle başarısızlık gözlenmezken, ${ }^{8}$ aynı mater- yalin Sınıf 1 ve Sınıf 2 kavitelerdeki başarısını değer- lendiren prospektif bir diğer çalışmada 3 yılda 1 restorasyonda, 4 yılda ise 2 restorasyonda retansiyon kaybı gözlenmiştir. ${ }^{12}$

Retansiyon kaybı gözlenen 3 Cis restorasyondan 2 tanesinin derinliği 2 mm'den azdı. Sığ lezyonlarda retantif alanın çok az olması restoratif materyallerin uygulanmasını zorlaştırmaktadır. Özellikle yüksek viskoziteli cam iyonomer simanın tek tabaka halinde uygulanması ve çok çabuk sertleşmesi lezyon yüzeyine iyi adapte olmasını engellemiş olabilir.

Bir yıl sonunda 2 Cis restorasyonun yüzey parlaklığında hafif matlaşma şeklinde bir azalma gözlenmiştir. Çalışmalarda, düşük fiziksel özellik göstermesi muhtemel cam iyonomerlerin, yüzeydeki mikropöröziteleri doldurarak plak birikimini azaltacağı düşüncesiyle rezin içerikli bir vernikle örtülenmesi önerilmektedir. Vernik uygulaması aynı zamanda restorasyonun estetik özelliklerini de iyileştirmektedir. Ancak rezin içerikli verniğin zamanla aşınması muhtemeldir. Çalışmamızda Cis grubunun yüzey parlaklığı skorlarındaki azalma rezin içerikli yüzey verniğinin zamanla aşınmasına bağlanmaktadır.

ADA standartlarına göre adeziv materyalin profesyonel kullanımda klinik olarak kabul edilebilir olması için 6 aylık takip sonrasında \%5'den, 18 aylık takip sonrasında ise $\% 10^{\prime}$ dan daha az retansiyon kaybı göstermesi gerekmektedir. ${ }^{21}$ Bizim çalışmamızda bu oran yüksek viskoziteli cam iyonomer restoratif materyal için 1. yılda \%4 olarak bulunmuştur. Dolayısıyla bu çalışmada, yüksek viskoziteli cam iyonomerlerin çürüksüz servikal lezyonlardaki 1 yıllık klinik performansı başarılı bulunmuştur.

\section{SONUÇ}

Çürüksüz servikal lezyonlarda test edilen yüksek viskoziteli cam iyonomer simanın 1 yıllık klinik performansı, kullanılan nanohibrit kompozit rezinle benzer bulunmuştur. Ancak, yüksek viskoziteli cam iyonomerlerin çürüksüz servikal lezyonlarda daimi restoratif materyal olarak kompozitlere alternatif oluşturup oluşturamayacağının belirlenmesi için uzun dönemli klinik çalışmalara mutlaka intiyaç vardır.

\section{KAYNAKLAR}

1. Osborne-Smith $\mathrm{KL}$, Burke FJ, Wilson $\mathrm{NH}$. The Aetiology of the Non-carious Lesion. Int Dent J 1999;49:139-43.

2. Bader JD, Mc Clure F, Scurria MS, Shugars DA, Heymann HO. Case- control Study of Non-carious Cervical Lesions. Community Dent Oral Epidemiol 1996;24:286-91.

3. Levitch LC, Bader JD, Shugars DA, Heymann HO. Non-carious Cervical Lesions. J Dent 1994;22:195207.

4. Heymann HO, Sturdevant JR, Brunson WD, Wilder $A D$, Sluder TB, Bayne SC. Twelve-month Clinical Study of Dentinal Adhesives in Class $V$ Cervical Lesions. J Am Dent Assoc 1993;12:53-78.

5. Van Meerbeek B, Braem M, Lambrechts $P$, Vanherle G. Evaluation of Two Dentin Adhesives in Cervical Lesions. J Prosthet Dent 1993;70:308-14.

6. Kaya T, Tirali RE. Cam İyonomer Simanlardaki Gelişmeler. Atatürk Üniv. Diş Hek Fak Derg 2013; 7: 71-7.

7. Diem VTK, Tyas MJ, Ngo HC, Phuong LH, Khanh ND. The effect of a Nano-filled Resin Coating on the 3-year Clinical Performance of a Conventional High-viscosity Glass-ionomer Cement. Clin Oral Investig 2014;18:753-9.

8. K Friedl, Hiller KA, Friedl KH. Clinical Performance of a New Glass Ionomer Based Restoration System: A Retrospective Cohort Study. Dent Mater 2011;27:1031-7.

9. Lohbauer U, Krämer N, Siedschlag G, Schubert EW, Lauerer B, Müller FA, Petschelt A, Ebert J. Strength and Wear Resistance of a Dental Glassionomer Cement with a Novel Nanofilled Resin Coating. Am J Dent 2011;24:124-8.

10. Turkun LS, Kanik O. Clinical Evaluation of New Glass Ionomer-coating Combinated Systems for 18 Months. Abstract 402 - IADR 2010, Barcelona, Spain.

11. Lohbauer U. Dental Glass Ionomer Cements as Permanent Filling Materials? - Properties, Limitations and Future Trends. Materials 2010;3:76-96.

12. Gurgan S, Kutuk ZB, Ergin E, Oztas SS, Cakir FY. Four-year Randomized Clinical Trial to Evaluate the Clinical Performance of a Glass Ionomer Restorative System. Oper Dent 2015;40:134-43. 
13. Cvar JF, Ryge G. Reprint of Criteria for the Clinical Evaluation of Dental Restorative Materials. 1971. Clin Oral Investig 2005;9:215-32.

14. Kanık EA, Taşdelen B, Erdoğan S. Randomization in Clinical Trials. Marmara Med J 2011;3:149-55.

15. Kim J, Shin W. How to Do Random Allocation (Randomization). Clin in Orthoped Surg 2014; 6:103-9.

16. Hickel R, Peschke A, Tyas M, Mjör I, Bayne S, Peters M, Hiller KA, Randall R, Vanherle G, Heintze SD. FDI World Dental Federation - Clinical Criteria for the Evaluation of Direct and Indirect Restorations. Update and Clinical Examples. J Adhes Dent 2010;12:259-72.

17. Mitra SB, Wu D, Holmes BN. An Application of Nanotechnology in Advanced Dental Materials. J Am Dent Assoc 2003;134:1382-90.

18. Yap AU, Tan $\mathrm{CH}$, Chung SM. Wear Behavior of New Composite Restoratives. Oper Dent 2004;29:26974.

19. Stewardson DA, Thornley $P$, Bigg T, Bromage C, Browne A, Cottam D, Dalby D, Gilmour J, Horton J, Roberts E, Westoby L, Creanor S, Burke $\mathrm{T}$. The Survival of Class $\mathrm{V}$ Restorations in General Dental Practice. Part 2, Early Failure. $\mathrm{Br}$ Dent J 2011;10:210-1.

20. De Moor RJ, Stassen IG, van 't Veldt $Y$, Torbeyns D, Hommez GM. Two-year Clinical Performance of Glass Ionomer and Resin Composite Restorations in Xerostomic Head- and Neck-irradiated Cancer Patients. Clin Oral Investig 2011;15:31-8.

21. American Dental Association Council on Scientific Affairs: Revised American Dental Association Acceptance Program Guidelines: Dentin and Enamel Adhesives. American Dental Association 2001;1-9.

\section{Yazışma Adresi:}

Doç. Dr. Esra UZER ÇELİK

İzmir Kâtip Çelebi Üniversitesi Diş Hekimliği Fakültesi Restoratif Diş Tedavisi A.D.

Aydınlık Evler Mahallesi, Cemil Meriç Caddesi, 6780 Sokak. No:48, 35640-Çiğli / İZMİR

Tel: +90 (232) 3254040

Fax: +90 (232) 3252535

E-mail: esrauzer@yahoo.com 